\title{
Disruption of the Axonal Trafficking of Tyrosine Hydroxylase mRNA Impairs Catecholamine Biosynthesis in the Axons of Sympathetic Neurons
}

\author{
${ }^{\circ}$ Armaz Aschrafi, ${ }^{1}$ Anthony E. Gioio, ${ }^{1}{ }^{-}$Lijin Dong, ${ }^{2}$ and Barry B. Kaplan ${ }^{1}$
}

\section{DOI:http://dx.doi.org/10.1523/ENEURO.0385-16.2017}

${ }^{1}$ Laboratory of Molecular Biology Division of Intramural Research Programs, National Institute of Mental Health National Institutes of Health, Bethesda, MD 20892, and ${ }^{2}$ Genetic Engineering Core, National Eye Institute National Institutes of Health, Bethesda, MD 20892

\begin{abstract}
Tyrosine hydroxylase $(\mathrm{TH})$ is the enzyme that catalyzes the rate-limiting step in the biosynthesis of the catecholamine neurotransmitters. In a previous communication, evidence was provided that TH mRNA is trafficked to the axon, where it is locally translated. In addition, a 50-bp sequence element in the 3' untranslated region (3'UTR) of TH mRNA was identified that directs TH mRNA to distal axons (i.e., zip-code). In the present study, the hypothesis was tested that local translation of $\mathrm{TH}$ plays an important role in the biosynthesis of the catecholamine neurotransmitters in the axon and/or presynaptic nerve terminal. Toward this end, a targeted deletion of the axonal transport sequence element was developed, using the lentiviral delivery of the CRISPR/Cas9 system, and two guide RNA (gRNA) sequences flanking the 50-bp cis-acting regulatory element in rat superior cervical ganglion (SCG) neurons. Deletion of the axonal transport element reduced TH mRNA levels in the distal axons and reduced the axonal protein levels of $\mathrm{TH}$ and $\mathrm{TH}$ activity as measured by phosphorylation of SER40 in SCG neurons. Moreover, deletion of the zip-code diminished the axonal levels of dopamine (DA) and norepinephrine (NE). Conversely, the local translation of exogenous TH mRNA in the distal axon enhanced TH levels and activity, and elevated axonal NE levels. Taken together, these results provide direct evidence to support the hypothesis that TH mRNA trafficking and local synthesis of TH play an important role in the synthesis of catecholamines in the axon and presynaptic terminal.
\end{abstract}

Key words: 3'untranslated region; CRISPR Cas9; dopamine; local translation; mRNA trafficking; superior cervical ganglion

\section{Significance Statement}

Tyrosine hydroxylase (TH) is the rate-limiting enzyme in the biosynthesis of the catecholamine neurotransmitters. Previous results suggested that TH mRNA is trafficked to the distal axons of primary sympathetic neurons and is locally translated. In the present study a gene editing strategy was employed to delete the axonal TH mRNA trafficking regulatory element (i.e., zip-code). Deletion of the zip-code reduced TH mRNA levels in the distal axons, reduced axonal protein levels of TH and diminished the axonal levels, and release of norepinephrine (NE). Collectively, these studies demonstrate that the local synthesis of TH plays an important role in catecholamine synthesis and may facilitate the maintenance of catecholamine levels in response to long-term alteration in the need for neurotransmitters. 


\section{Introduction}

It is now evident that one of the mechanisms used by axons and presynaptic nerve terminals to rapidly respond to extracellular cues is to temporally and spatially regulate protein expression by asymmetrical mRNA transport and localized translation (Gomes et al., 2014; Jung et al., 2014). Transport of mRNAs into the distal axons enables coordination of local changes in the presynaptic proteome, a process critical in directing the growth cones of immature axons and ensuring neuronal survival (Fallini et al., 2016). These axonal mRNAs code for several functional categories of proteins including: cytoskeletal elements, ribosomal proteins and translation factors, transcription factors, as well as metabolic enzymes and nuclear-encoded mitochondrial mRNAs (Scott et al., 2015). The targeting of specific mRNAs to the distal structural/functional domains of the neuron is driven by sequence motifs located in the 3'untranslated region (3'UTR) of the RNA itself, which are recognized by specialized RNA-binding proteins (RBPs; Smart et al., 2007). These cis-acting regulatory elements or "zipcodes" contain localization signals (Aschrafi et al., 2010). The motifs can be constituted by either the primary sequence of the mRNA, or its higher order structure, such as a hairpin or stem-loop (Aschrafi et al., 2010; Di Liegro et al., 2014).

In addition to mRNAs coding for structural, mitochondrial, ribosomal proteins, and translation regulatory elements, there is considerable evidence to suggest that mRNAs encoding proteins involved in neurotransmitter synthesis are present in the axon. Recent research suggested that tyrosine hydroxylase $(\mathrm{TH}) \mathrm{mRNA}$ is localized to axons of sympathetic neurons, and demonstrated that its local translation facilitates axonal dopamine (DA) synthesis (Gervasi et al., 2016). The finding that TH mRNA is present in axons of primary sympathetic neurons is consistent with the detection of TH mRNA in brain regions innervated by catecholaminergic terminals (Lewis et al., 1991; Melia et al., 1994). In the adult rat brain, the presence of TH mRNA transcripts was reported in the cerebellum, striatum, and pituitary neurointermediate lobe, all regions that are devoid of catecholamine-synthesizing cells, but receive significant catecholaminergic innervation (Melia et al., 1994). Moreover, a 50-bp sequence

Received December 28, 2016; accepted May 17, 2017; First published May 26, 2017.

The authors declare no competing financial interests.

Author contributions: A.A., A.E.G., L.D., and B.B.K. designed research; A.A., A.E.G., L.D., and B.B.K. analyzed data; A.E.G. contributed unpublished reagents/analytic tools; A.A. and B.B.K. wrote the paper.

This work was supported by the Division of Intramural Research Programs of the National Institute of Mental Health Grant ZIA-MH002768.

Acknowledgements: We thank Cai Chen, Ching-Yu Sun, Jenna Gale, and Jingqi Lei for invaluable technical assistance.

Correspondence should be addressed to Barry B. Kaplan, Laboratory of Molecular Biology, Division of Intramural Research Programs, National Institute of Mental Health, National Institutes of Health, Bethesda, MD 20892, E-mail: kaplanb@mail.nih.gov.

DOI:http://dx.doi.org/10.1523/ENEURO.0385-16.2017

Copyright (C) 2017 Aschrafi et al.

This is an open-access article distributed under the terms of the Creative Commons Attribution 4.0 International license, which permits unrestricted use, distribution and reproduction in any medium provided that the original work is properly attributed. element in the 3'UTR of TH mRNA that directs TH mRNA to distal axons has been identified (Gervasi et al., 2016). This TH mRNA zip-code was also shown to be sufficient to mediate the trafficking of a reporter mRNA to distal axons of sympathetic neurons.

Traditional approaches to studying the functionality of cis-acting regulatory sequences that control cellular mRNA trafficking in vitro involve overexpression of sequences linked to a reporter gene (Kaplan et al., 2009). These experiments are hampered by the out-of-genomiccontext, in which the noncoding elements are studied, as well as untoward consequences of introducing abnormally high levels of foreign DNA sequences that could perturb endogenous gene expression and basic neuronal function (Han et al., 2015). The CRISPR/Cas9 system has recently been harnessed as an RNA-guided nuclease method of genome editing in vitro and in vivo in several animal species (Hsu et al., 2014). While this programmable endonuclease approach to genome editing has been deployed numerous times to modify protein-coding genes, there has yet to be a report on its use in altering the regulatory elements controlling mRNA trafficking. Here, we employed the CRISPR-Cas9 system to test the hypothesis that the axonal trafficking of TH mRNA and its local translation plays an important role in the biosynthesis of the catecholamine neurotransmitters in the axon and/or presynaptic nerve terminal. The outcome of our studies clearly demonstrate that CRISPR-mediated genomic deletion of the axonal transport element of TH mRNA abolishes axonal trafficking of TH mRNA and diminishes presynaptic catecholamine synthesis and release in primary rat sympathetic neurons.

\section{Materials and Methods}

\section{Neuronal cell cultures}

Superior cervical ganglia (SCGs) were removed from 3-d-old Harlan Sprague Dawley rats of either sex and dissociated to single cell suspensions using gentleMACS Dissociator and Neuronal Tissue Dissociation kit (Miltenyi Biotec). The dissociated cells were plated in the center compartment of three-chamber Campenot culture dishes (Hillefors et al., 2007) or, for purpose of in situ hybridization histochemistry, onto Nunc Lab-Tek II-CC2 glass chamber slides (Sigma-Aldrich). Cells were cultured in serum-free Neurobasal medium (ThemoFisher) supplemented with $2 \% \mathrm{~B}_{27}$ supplement, $0.5 \mathrm{mM}$ L-glutamine (ThemoFisher), $25 \mu \mathrm{M}$ glutamic acid (Sigma-Aldrich), 50 $\mathrm{ng} / \mathrm{ml} \mathrm{NGF}, 20 \mathrm{mM} \mathrm{KCl}, 20 \mathrm{U} / \mathrm{ml}$ penicillin and $20 \mu \mathrm{g} / \mathrm{ml}$ streptomycin (Hyclone) for 3-14 d in vitro (DIV) before use. Medium was changed every 3-4 d. Two days after plating, 5-fluoro-2'-deoxyuridine $(50 \mu \mathrm{M})$ was added to the culture medium to inhibit growth of non-neuronal cells. After 7-14 DIV, distal axons were harvested from the side compartments of the culture chambers, which were devoid of neuronal soma or non-neuronal cells, as judged by phase-contrast microscopy.

\section{CRISPR design and synthesis}

To minimize off-target activity, the RNA-guided interspaced short palindromic repeats (CRISPR)-Cas9 nuclease 


\section{A}

5' CAC TGC TTC TCA ACC ATG TCT TAC TAC TGC ATG CAC TCC AGG GTG GTC CTG CAI TCC ICC TGC CCT CCA TGCTCT ATA CTA CCC TGA TTA TTC TCT CAA TAA AGG AAG GAA AGA TCT CCA 3 '

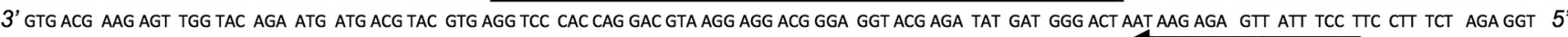

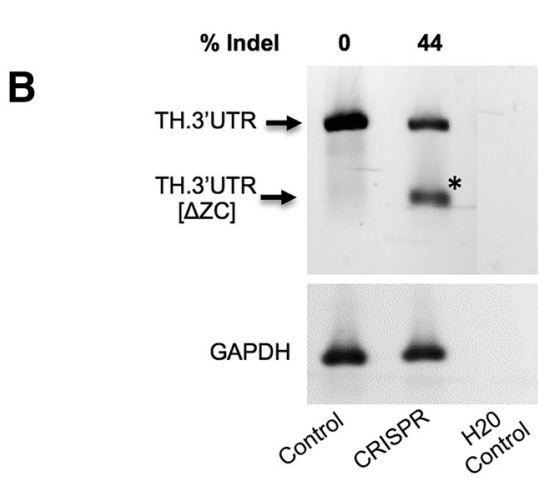

Figure 1. Axonal targeting sequence present in the rat TH mRNA can be removed by a lentiviral vector containing CRISPR/Cas9. $\boldsymbol{A}$, LentiCRISPR/Cas9-mediated deletion of the axonal targeting element (i.e., zip-code) of TH mRNA. Location of sgRNAs sequences targeting the flanking ends of the 50-bp region containing the axonal targeting sequence in the 3'UTR of rat TH mRNA. Diagram shows the gRNA-targeting sites. The 50-bp zip-code sequence is bolded. $\boldsymbol{B}$, PCR analysis of genomic DNA extracted from SCG neurons infected with lentiCRISPR (control) or sgRNA 1 and sgRNA 2 lentiCRISPR (CRISPR) virus. One week after infection, genomic DNA from the cells was extracted and amplified using PCR to test for the deletion of the 50-bp region. The faster migrating band (indicated by arrow) is the shortened TH allele. GAPDH was used as a loading control. The percentage of edited DNA that resulted in an indel (\% indel) was determined by quantitating the amount of uncut versus cut DNA (*).

system was combined with a double nicking strategy to introduce targeted DNA double-stranded breaks around the zip-code region. DNA targeting was performed using two CRISPR guide RNAs (gRNAs), which bound flanking regions of the 50-bp zip-code located in the 3'UTR of the TH gene (Fig. 1A). gRNAs were designed using an online CRISPR Design Tool (crispr.mit.edu), and generated by the slow annealing and phosphorylation of two complementary oligonucleotides (IDT) with T4 polynucleotide kinase (New England Biolabs) in a $10 \mu \mathrm{L}$ reaction mixture. gRNA1 forward oligo (Fw): 5' CACCGTTACTACTGCATGCACTCCA 3'; reverse oligo (Rv): 5' CAATGATGACGTACGTGAGGTCAAA 3'; gRNA2 Fw oligo: 5' CACCGCCTTTATTGAGAGAATAATC 3'; Rv oligo: 5' AAACGATTATTCTCTCAATAAAGGC 3' (target sequence is underlined). The pLentiCRISPR v.2 vector (AddGene) was digested using $\mathrm{BsmBI}$, and a 1:250 dilution of annealed oligos were cloned into the single gRNA scaffold of the linearized pLentiCRISPR vector backbone as described by (Sanjana et al., 2014). Plasmid purification and endotoxin removal for CRISPR constructs were performed using the GenElute HP Plasmid Maxiprep kit (SigmaAldrich). Correct orientation of the cloned gRNAs was confirmed using DNA Sanger sequencing. Cas9 cleavage efficiency was determined in primary SCG neurons 5-7 d after coinfection with the gRNA1 and gRNA2 containing lentiCRISPR. Genomic DNA was extracted and RNase A-treated using Gentra Puregene Cell kit (QIAGEN). Isolated genomic DNA was subjected to PCR amplification using primers that flanked the predicted Cas9 cut site regions, Fw: 5' CTGGACAGCCCTCACACCA 3', Rv: 5' GAACTATCTITGTGGTGACGCAG 3'. Amplicons from target cleavage sites were ligated into plasmids (JetClone kit, ThermoFisher) and transfected into high-efficiency DH $5 \alpha$ competent Escherichia coli cells (ThermoFisher) for DNA Sanger sequencing analysis of
8-10 clones, from which the ratios of genomic deletion were used to quantify cleavage efficiency.

\section{Lentivirus production}

Viral particles were prepared by cotransfection of HEK-293T cells with gRNA-cloned transfer lentiCRISPRv2 plasmids together with the packaging plasmids pVSVg (AddGene) and psPAX2 (AddGene) using Lipofectamine2000 (ThermoFisher). HEK293T cells were placed overnight in a $5 \% \mathrm{CO}_{2}$ humidified $37^{\circ} \mathrm{C}$ incubator. The following day, medium was replaced by fresh Ultraculture (Lonza) and supernatants were collected $24 \mathrm{~h}$ later. Viral particles were purified using a Lenti-X Maxi Purification kit (Takara) and stored at $-80^{\circ} \mathrm{C}$ until use.

\section{Constructs and SCG neuron transfection}

Full-length or zip-code-truncated TH mRNAs were synthesized as described by Gervasi et al. (2016). DNA oligonucleotides encoding the full-length rat TH ORF with the entire 3'UTR, or 3'UTR lacking the 50-bp zip-code sequence (IDT) were cloned after the T7-promoter of the pBLUE vector using the ECORI and HindllI restriction sites. Following vector linearization, using the Hindlll site, $5^{\prime}$ methyl cap containing TH mRNA was synthesized using the mMESSAGE mMACHINE T7 Transcription kit (Ambion). Purified TH mRNA $(0.5 \mu \mathrm{g})$ was transfected into distal SCG axons present in the lateral compartment of Campenot chambers using mRNA-In Neuro (GlobalStem).

\section{RNA isolation and quantitative reverse transcriptase PCR (qRT-PCR)}

RNA was isolated using Direct-Zol RNA MiniPrep (Zymo Reasearch) according to the manufacturer's instructions. Briefly, cells and proximal axons cultured in the central compartment of Campenot chambers or distal axons growing in the side compartments were lysed in $100 \mu$ l of TRIzol (ThermoFisher). An equal volume of ethanol was 
added to the homogenate and the mix was loaded onto a Zymo-Spin IIC Column and washed with Direct-Zol RNA PreWash and Wash buffers. The RNA sample was eluted in $35 \mu \mathrm{l}$ of water. On average, the concentration of the purified RNA was $15 \mathrm{ng} / \mu \mathrm{l}$ for RNA isolated from distal axons and $25 \mathrm{ng} / \mu$ l for RNA isolated from neuronal cell bodies and proximal axons. Reverse transcription was performed using RevertAid H Minus First Strand cDNA Synthesis kit (ThermoFisher). For qRT-PCR analysis, $2 \mu \mathrm{l}$ of 1:10 diluted cDNA was added to $10 \mu \mathrm{l}$ Fast SYBR green (Affymetrix) and $2 \mu$ l of QuantiTect primers (QIAGEN). For each experimental sample, the reaction was run in triplicate, using a StepOne Real-Time PCR system (ThermoFisher). The results were analyzed using the StepOne Software (ThermoFisher), normalizing target mRNA levels to $\beta$-actin mRNA levels. TH, GAPDH, and $\beta$-actin gene primers were QuantiTect validated primers (QIAGEN). The following primers we used For RT-PCR analysis of intact and zip-code-less TH mRNA: Fw: 5' ATCCAGCGCTCCTTGG, Rv: 5' AGATTCTTTCCTTCCTTTATTGAGA.

\section{In situ hybridization histochemistry}

In situ hybridization was performed on freshly fixed tissue using the RNAscope 2.5 High Definition-RED Assay (Advanced Cell Diagnostics) according to manufacturer's instructions. Cultured neurons were fixed in $20 \%$ paraformaldehyde (PFA) for 30 min, dehydrated in increasing concentrations of ethanol $(50 \%, 70 \%$, and $100 \%)$ and rehydrated (70\% ethanol, $50 \%$ ethanol, PBS) before applying Pretreat 1 and 1:15 diluted pretreat three reagents. $A$ target specific riboprobe (rat TH, RefSeq: NM_012740.3) was then hybridized overnight at $40^{\circ} \mathrm{C}$, followed by incubation with signal amplification reagents. The hybridized riboprobe was visualized with RED2.5 under either bright field or fluorescence microscopy using a Texas Red filter.

\section{Immunocytochemistry}

Neurons were fixed using 10\% PFA for 30 min. After washing, permeabilization was accomplished by incubation with $0.3 \%$ Triton X-100 in PBS for 3 min. Neurons were then blocked in 5\% bovine serum albumin (BSA) in PBS for 30 min at room temperature (RT) and incubated in primary antibody diluted in 3\% BSA-PBS for $4 \mathrm{~h}$ at RT or overnight at $4^{\circ} \mathrm{C}$. After incubation with the primary antibodies [anti-TH antibody, Cell Signaling, 1:1000; anti-phospho-TH (Ser40) antibody, Cell Signaling 2791S, 1:500; anti- $\beta$-actin antibody, Cell Signaling, 1:1000; anti-dopamine (DA) antibody, Abcam, 1:1000; anti-norepinephrine (NE) antibody, Abcam, $1: 1000]$, neurons were washed in $0.1 \%$ Triton X-100 PBS, incubated in secondary antibody [Alexa Fluor 594 (or 488) goat anti-mouse or goat anti-rabbit] for $1 \mathrm{~h}$ at $\mathrm{RT}$ and visualized using an EVOS fluorescence microscope.

\section{Western blot analysis}

Axon or soma were lysed in RIPA buffer (Sigma-Aldrich) containing anti-peptidase cocktail (Roche). Lysates were heated in LDS sample buffer and $1 \mathrm{mM}$ dithiothreitol, and separated on NuPAGE Novex 4-12\% Bis-Tris Gels (ThermoFisher). Proteins were transferred to a Odyssey nitrocellulose membrane (LI-COR Biosciences), and membranes were blocked with Odyssey blocking buffer (LI-COR Biosci- ences) for $1 \mathrm{~h}$. Proteins were detected by overnight incubation at $4^{\circ} \mathrm{C}$ with antibodies against $\mathrm{TH}$ (Cell Signaling, dilution 1:1000), anti-phospho-TH (Ser40) antibody (Cell Signaling, dilution 1:500), or $\beta$-actin (Cell Signaling, dilution $1: 1000$ ) in Odyssey blocking buffer containing $0.2 \%$ Tween 20 for either $2 \mathrm{~h}$ at RT or overnight at $4^{\circ} \mathrm{C}$, followed by incubation with a IRDye $800 \mathrm{CW}$-conjugated goat anti-rabbit IgG (LI-COR Biosciences) at a 1:5000 dilution in Odyssey blocking buffer containing $0.2 \%$ Tween 20 and $0.1 \%$ SDS for $1 \mathrm{~h}$ at RT. The membrane was washed 3 times with Tris-buffered saline/0.1\% Tween 20 (TBS-T) between each incubation step. The membrane was then imaged with the Odyssey Infrared Imaging System (LI-COR Biosciences).

\section{Measurement of NE release}

Primary SCG neurons grown in Campenot chambers (DIV 14) were infected with the empty lentiCRSPR or the gRNA-containing lentiCRISPR. One week after infection, cells were depolarized by the addition of $100 \mathrm{mM} \mathrm{KCl}$ into the distal axon-containing lateral compartment of Campenot chambers for $10 \mathrm{~min}$. Culture media was collected and NE was measured using the Norepinephrine Research ELISA kit (Rocky Mountain) in accordance with the manufacturer's instructions. Briefly, NE is bound to the solid phase of the microtiter plate. Acylated NE from the sample and solid phase-bound noradrenaline compete for a fixed number of antiserum binding sites. When the system is in equilibrium, free antigen and free antigen-antiserum complexes are removed by washing. The antibody bound to the solid phase NE was detected by anti-rabbit lgG/peroxidase. The substrate $\mathrm{TMB} /$ peroxidase reaction was monitored at $450 \mathrm{~nm}$. The amount of antibody bound to the solid phase NE is inversely proportional to the NE concentration of the sample. Absorbance data were analyzed by linear regression analysis to calculate release NE levels.

\section{Bioinformatics and statistical analysis}

The quantitative analyses of Western blot protein bands and cellular fluorescence signals, following reporter transfection and immunocytochemistry, was performed using ImageJ software as described previously (Burgess et al., 2010; McCloy et al., 2014). Quantitative data are presented as the mean \pm SEM. Student's $t$ test or one-way ANOVA with Bonferroni multiple comparison was used for two- or three sample comparisons, respectively. Statistical significance was set at $\alpha=0.05$ for all experiments. Statistical analyses were performed using Microsoft Excel and GraphPad.

\section{Results}

\section{CRISPR-mediated genome editing of axonal trafficking sequences located in the 3'UTR of TH mRNA}

Previously, we employed chimeric fluorescent reporter constructs and identified a sequence element within the TH 3'UTR that is required for the axonal localization of the reporter mRNA (Gervasi et al., 2016). These results provided the first direct evidence that TH mRNA is trafficked to the axon under the direction of a cis-acting regulatory element situated in the 3'UTR of the mRNA. Results derived from cell fractionation experiments and PCR analy- 
ses established that TH mRNA was present in axonal polysomes. In addition, findings obtained from metabolic labeling studies demonstrated that the TH mRNA was locally translated. Based on these observations, it was hypothesized that the local translation of $\mathrm{TH}$ is critical for axonal TH activity and consequently the biosynthesis of the catecholamine neurotransmitters in the axon and/or presynaptic nerve terminal. To evaluate this postulate, we designed and tested paired RNA-guided CRISPRassociated nuclease Cas9 for introducing a targeted loss-of function deletion of the zip-code located in the 3'UTR of the TH gene. Lentiviral vectors were used for the delivery of two separate gRNAs directed to $5^{\prime}$ and $3^{\prime}$ ends of the zip-code (Fig. 1A). Infection of primary SCG neurons with Cas 9 coupled gRNAs resulted in the deletion of the zip-code in $44 \%$ of the $\mathrm{TH}$ loci as detected by genomic PCR analyses (Fig. 1B).

\section{Deletion of the zip-code diminishes TH mRNA levels in the axon and reduces local TH synthesis and phosphorylation}

To assess whether the deletion of the zip-code affects axonal trafficking of TH mRNA, SCG neurons cultured in Campenot chambers were infected with viral particles encoding gRNAs/cas9 (CRISPR) or cas9 (control), and a RT-PCR analysis of the total RNA isolated from the axons and the infected somas was performed. Agarose gel fractionation of the RT-PCR products revealed that CRISPRinfected neurons produced both intact and zip-code-less $\mathrm{TH}$ mRNA (TH[$[\Delta \mathrm{ZC}])$, with the $\mathrm{TH}[\Delta \mathrm{ZC}]$ mRNA detected solely in the soma of SCG neurons, whereas the fulllength TH mRNA was PCR amplified from the soma and axonal RNA (Fig. 2A). The subsequent qRT-PCR analyses confirmed that, unlike the reduced TH mRNA quantities obtained in the distal axons of CRISPR-infected neurons (mean $0.06 \pm 0.01$ control vs $0.01 \pm 0.002$ CRISPR relative quantity, $p \leq 0.01$; Fig. $2 B$ ), nearly equal amounts of the $\mathrm{TH}$ transcripts were present in the cell bodies $5 \mathrm{~d}$ after CRISPR infection (mean $0.14 \pm 0.01$ control vs 0.13 \pm 0.01 CRISPR relative quantity, $p \leq 0.51$; Fig. $2 C$ ), indicating that genomic deletion of the zip-code selectively reduces the abundance of axonal TH mRNA. These findings confirm previous results that the 50-bp zip-code is essential for the axonal localization of TH mRNA (Gervasi et al., 2016).

To confirm the absence of TH mRNA in axons of CRISPR-infected neurons, we used in situ hybridization histochemistry. In these experiments, the TH mRNA hybridization signal appeared as discrete puncta along the entire length of the axon bundles of control neurons (Fig. 2D). In contrast, no signal was detected in the axons of CRISPR-treated neurons, with most of the TH signal confined to the cell bodies (Fig. 2E). Measurement of the number of TH positive puncta as a function of axon length revealed that their number decreased by $\sim 50 \%$ in the axons of CRISPR-treated neurons as compared with control axons (Fig. 2G). In addition, the hybridization signal for the mRNA encoding an endoplasmic reticulum localized protein, peptidylprolyl isomerase $B$ (Ppib), was restricted to the cell body, indicating that the $\mathrm{TH}$ signal detected in axons was due specifically to transport of $\mathrm{TH}$ mRNA (Fig. 2F).

To assess whether the CRISPR-mediated inhibition of axonal TH mRNA trafficking also resulted in reduced local synthesis and phosphorylation of $\mathrm{TH}$, immunocytochemistry was employed to examine the levels of $\mathrm{TH}$ protein. Additionally, the phosphorylation of TH at Ser40 (phospho$\mathrm{TH})$ was monitored, since previous findings suggested that Ser40 phosphorylation is indicative of increased TH activity (Bevilaqua et al., 2001; Bobrovskaya et al., 2004). Both TH and phospho-TH levels were decreased by in the distal axons of CRISPR-infected neurons as compared with control neurons (TH: mean 84,000 \pm 9780 control vs 49,240 \pm 5030 CRISPR relative fluorescent intensity, $p \leq 0.002$; phospho-TH: mean 278,800 $\pm 21,800$ control vs 60,280 \pm 6463 CRISPR relative fluorescent intensity, $p \leq 0.0001$; Fig. $3 A-C)$. Similar to the observation made for TH mRNA, while a decrease in $\mathrm{TH}$ and phospho-TH protein levels were detected in the distal axons of CRISPR-infected neurons, TH and phosphor-TH protein levels in the parental soma were little altered (TH: mean 73,290 \pm 6047 control vs 62,210 \pm 5314 CRISPR relative fluorescent intensity, $p \leq 0.17$; phospho-TH: mean 81,240 \pm 4067 control vs 87,780 \pm 2377 CRISPR relative fluorescent intensity, $p \leq 0.18$; Fig. $3 A, D, E$ ). Consistent with the immunocytochemistry findings, Western blot analysis of $\mathrm{TH}$ and phospho- $\mathrm{TH}$ in axonal and parental cell soma $7 \mathrm{~d}$ after viral infection showed reduced axonal levels of $\mathrm{TH}$ and phospho- $\mathrm{TH}$, whereas their levels were unchanged in the parental soma [TH (axon): mean 230,700 \pm 21420 control vs 69,980 \pm 1669 CRISPR normalized protein levels, $p \leq 0.002$; phospho-TH (axon): mean 206,300 \pm 5487 control vs 118,400 \pm 3862 CRISPR normalized protein levels, $p \leq 0.0002$; TH (soma): mean $302,300 \pm 46,380$ control vs $347,500 \pm 47,190$ CRISPR normalized protein levels, $p \leq 0.53$; phospho-TH (soma): mean $538,500 \pm 30,640$ control vs 497,300 $\pm 19,300$ CRISPR normalized protein levels, $p \leq 0.32$; Fig. $3 F-H$ ]. These findings indicate that axonal trafficking of $\mathrm{TH}$ mRNA is critical for its local translation and activity in distal axons and nerve endings.

\section{Impaired axonal transport and local translation of $\mathrm{TH}$ mRNA reduces local catecholamine neurotransmitter levels}

Since $\mathrm{TH}$ is the rate-limiting enzyme in catecholamine biosynthesis, we examined whether CRISPR-mediated ablation of axonal mRNA trafficking and local synthesis of $\mathrm{TH}$ affects catecholamine synthesis. Toward this end, SCG neurons cultured in Campenot chambers were infected with CRISPR or control viral particles, and $7 \mathrm{~d}$ after infection DA and NE levels were monitored using immunocytochemistry. DA and NE levels decreased by $\sim 70 \%$ in distal axonal compartments when compared with their levels in the axons of control neurons (DA: mean 84,100 \pm 5840 control vs $26,310 \pm 2173$ CRISPR relative fluorescent intensity, $p \leq 0.0001$; NE: mean 13,680 \pm 512.4 control vs $4606 \pm 243.0$ CRISPR relative fluorescent intensity; $p \leq 0.0001$; Fig. $4 A-C$ ). The measurement of DA and NE levels in the soma of CRISPR and control-infected 
A

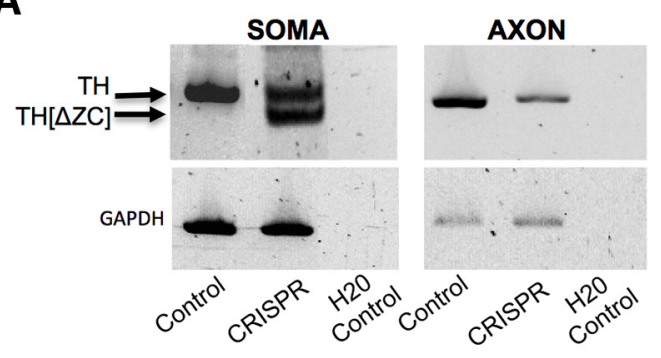

B

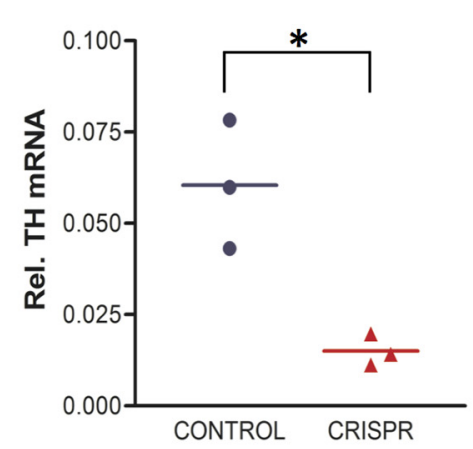

C

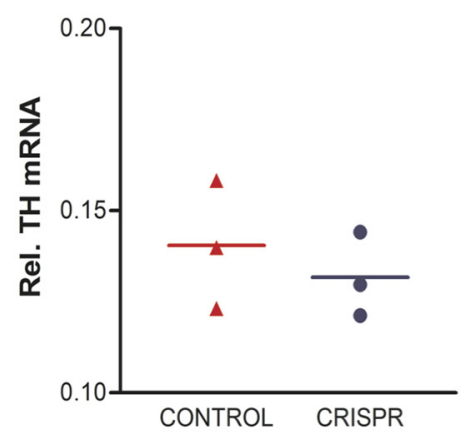

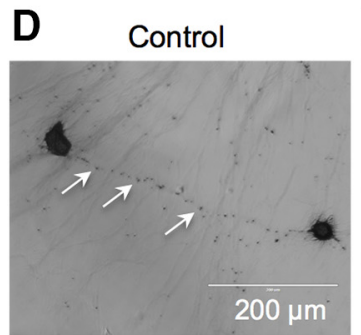

E CRISPR
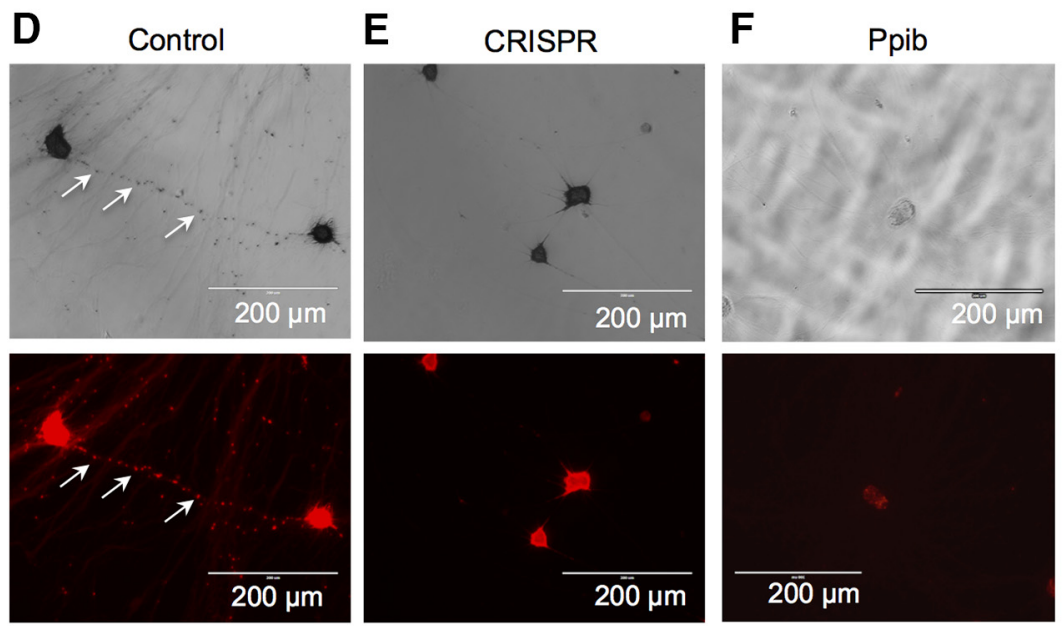

G

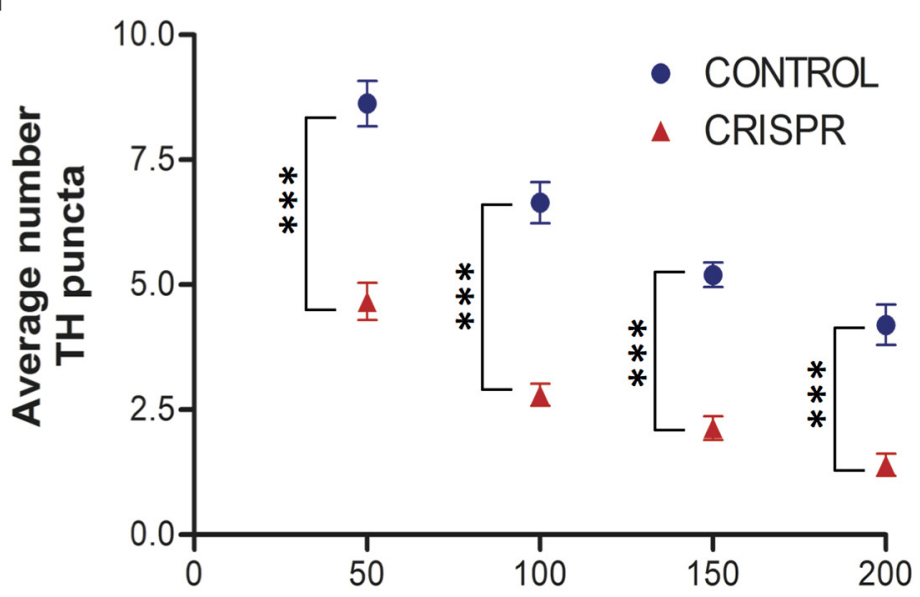

Distance from soma $[\mu \mathrm{m}]$

Figure 2. Deletion of the axonal transport element (zip-code) of TH mRNA significantly reduces TH mRNA levels in the axon. $\boldsymbol{A}, \mathrm{RT}-\mathrm{PCR}$ analysis of intact and zip-code (ZC)-less TH mRNA in the axons and soma of SCG neurons one week after lentiCRISPR (control) or sgRNA 1 and sgRNA 2 lentiCRISPR (CRISPR) virus infection. Total RNA from the axons and soma of SCG neurons cultured in Campenot culture dishes was extracted, RNA was reverse transcribed into cDNA, and TH cDNA was amplified using PCR to examine the presence of intact and zip-code-less mRNA in the axons and soma of SCG neurons. GAPDH was used as a loading control. PCR amplification products were fractionated on a $4 \%$ agarose gel and visualized using an ultraviolet (UV) light. CRISPRinfected neurons produce both intact and zip-code-less TH mRNA, with zip-code-less TH mRNA detected only in the soma of SCG neurons. B, C, Quantification of TH mRNA levels in the distal axons and soma of SCG neurons infected with lentiCRISPR (control) or sgRNA 1 and sgRNA 2 containing lentiCRISPR (CRISPR). TH mRNA levels were determined by qRT-PCR one week after viral infection, using total RNA samples prepared from SCG axons and soma and gene-specific primers for TH. The relative levels of TH transcript were normalized to $\beta$-actin mRNA to provide an internal control for reverse transcription and axonal density. Data are the 
continued

mean $\pm \operatorname{SEM}(n=3) . * p \leq 0.01$. $\boldsymbol{D}, \boldsymbol{E}$, In situ hybridization analysis of single axons from dissociated primary SCG neurons grown in monolayer cell culture. In axons hybridized with a TH-specific riboprobe, TH mRNA appears as discrete puncta, whereas CRISPRmediated deletion of the zip-code of TH mRNA abolishes TH puncta in the distal axons of primary SCG neurons. Arrows denote TH mRNA puncta in the axon. $\boldsymbol{F}$, mRNA for Ppib, an endoplasmic reticulum-associated protein, is not localized to the axons. $\boldsymbol{G}$, The number of TH mRNA containing granules is decreased in CRISPR neurons as compared with control neurons. Data are mean \pm SEM from the measurement of 35-45 axons. TH mRNA containing puncta are measured as a function of axon length. The experiment was repeated three times with similar results. Student's $t$ test, $* * * p \leq 0.0001$

neurons suggested that the reduction of catecholamine is restricted to the distal axons of SCG neurons, as no differences in the levels of soma DA and NE could be detected (DA: mean 66,370 \pm 2670 control vs $62,860 \pm$ 1715 CRISPR relative fluorescent intensity, $p \leq 0.29$; NE: mean $12,410 \pm 613.3$ control vs $12,860 \pm 388.8$ CRISPR relative fluorescent intensity, $p \leq 0.54$; NE: mean 13,680 \pm 512.4 control vs $14,606 \pm 243.0$ CRISPR relative fluorescent intensity; $p \leq 0.52$; Fig. $4 A, D, E)$. Additionally, CRISPR-mediated inhibition of axonal TH mRNA trafficking and local synthesis resulted in an $\sim 50 \%$ reduction in NE release from the nerve endings of sympathetic neurons as assessed by an immunoassay (mean $20.73 \pm 1.797$ control vs $9.783 \pm$ 1.464 CRISPR, $p \leq 0.003$; Fig. $4 F$ ). These data provide evidence that the axonal trafficking and local translation of TH mRNA is contributing significantly to the synthesis of catecholamines in the axons of sympathetic neurons.

\section{Overexpression of the synthesis of TH mRNA in distal axons enhances local NE synthesis}

CRISPR-mediated genome editing of the TH mRNA zip-code abolished axonal TH mRNA abundance and reduced its local translational activity. To further assess this finding, we examined whether the local overexpression of TH augmented cathecholamine synthesis. Toward this end, TH mRNA was transfected into the distal axons of SCG neurons and levels of TH and phospho-TH, as well as NE levels were assessed using immunocytochemistry. Transfection with TH mRNA resulted in an $\sim 2.5$-fold increase in axonal $\mathrm{TH}$ protein levels compared with the endogenous TH levels in sham-transfected neurons (mean 26,240 \pm 2046 control vs 61,190 \pm 6028 TH mRNA transfected, relative fluorescent intensity, $p \leq 0.0001$; Fig. $5 A, B)$. In addition, $\mathrm{TH}$ phosphorylation at Ser40 in distal axons increased 2.5-fold above control levels neurons (mean $7059 \pm 1147$ control vs $17,780 \pm 812.4$ TH mRNA transfected, relative fluorescent intensity, $p \leq 0.0001$; Fig. $5 A, C)$. In contrast, no significant differences in TH protein levels and TH phosphorylation at Ser40 were detected in the parental cell soma of sympathetic neurons (TH: mean $41,440 \pm 1922$ control vs $38,780 \pm 1828 \mathrm{TH}$ mRNA transfected, relative fluorescent intensity, $p \leq 0.32$; phospho-TH: mean $27,350 \pm 1288$ control vs $28,470 \pm 1777$ TH mRNA transfected, relative fluorescent intensity, $p \leq$ 0.61 ; Fig. $5 A, E, F)$. These findings suggest that enhanced $\mathrm{TH}$ enzymatic activity is restricted to distal axons on local synthesis of TH. To examine whether increased local TH synthesis contributed to elevation of catecholamine levels, NE levels were monitored $24 \mathrm{~h}$ after transfecting the distal axons with TH mRNA. As shown in Figure $5 A, D$, NE levels increased 5.5-fold in distal axonal compartments when compared with NE levels in sham-transfected axons (mean 17,660 \pm 2216 control vs 107,100 $\pm 30,860 \mathrm{TH}$ mRNA transfected, relative fluorescent intensity, $p \leq$ 0.004). In contrast, NE levels remained unaltered in the parental cell soma (mean 30,100 \pm 1982 control vs $26,430 \pm 1795 \mathrm{TH}$ mRNA transfected, relative fluorescent intensity, $p \leq 0.18$; Fig. $5 A, G$ ).

To extend the investigation of the local $\mathrm{TH}$ synthesis and activity, and to examine whether the axonal zip-code element is required for local TH protein synthesis, the full-length TH mRNA or a zip-code-less TH $(\mathrm{TH}[\Delta \mathrm{ZC}])$ mRNA were transfected into the distal axons of SCG neurons and the levels of TH and NE were measured in the axon and soma using immunocytochemistry. Transfection of axons with the intact or zip-code-truncated $\mathrm{TH}$ mRNAs resulted in significant elevation of the TH protein levels in the axons of SCG neurons $24 \mathrm{~h}$ after mRNA lipofection (mean $5213.54 \pm 320.03$ control vs 15,240.13 \pm 1027 TH mRNA transfected, 27,302.87 $\pm 1306.7 \mathrm{TH}[\Delta \mathrm{ZC}]$ mRNAs transfected, relative fluorescent intensity, $p \leq$ 0.0001; Fig. $6 B, C)$. In contrast, no significant differences in $\mathrm{TH}$ protein levels were detected in the parental cell soma of axons lipofected with full-length or zip-codeless TH mRNAs (mean 21,966.00 \pm 657.74 control vs $19,505.47 \pm 919 \mathrm{TH}$ mRNA transfected, 17,748.53 \pm $715.77 \mathrm{TH}[\Delta \mathrm{ZC}]$ mRNAs transfected, relative fluorescent intensity, $p \leq 0.0001$ ). Consistent with the previous observation that local synthesis of $\mathrm{TH}$ results in enhanced $\mathrm{NE}$ levels, transfection of axons with the truncated $\mathrm{TH}$ mRNA also resulted in elevated axonal NE levels (mean $9901.33 \pm 486.88$ control vs $133,099.93 \pm 524.67 \mathrm{TH}$ mRNA transfected, $13,167.33 \pm 537.20 \mathrm{TH}[\Delta \mathrm{ZC}] \mathrm{mRNAs}$ transfected, relative fluorescent intensity, $p \leq 0.0001$ ), whereas soma NE levels were marginally elevated, albeit not significantly, as compared with control levels (mean $8731.20 \pm 292.11$ control vs $11,210.87 \pm 627.17 \mathrm{TH}$ mRNA transfected, $9431.6 \pm 257.83 \mathrm{TH}[\Delta \mathrm{ZC}]$ mRNAs transfected, relative fluorescent intensity; Fig. $6 B, D$ ). To examine whether intact or truncated TH mRNA can be locally translated in the soma and proximal axons, the center compartment of the Campenot chambers harboring the soma and proximal axons of SCG neurons were transfected with the full-length or zip-code-less $\mathrm{TH}$ mRNA. One day after transfection, pronounced levels of $\mathrm{TH}$ protein and NE were measured in the soma and proximal axons of SCG neurons, whereas the levels of $\mathrm{TH}$ and NE remained unchanged in the distal axons [TH (soma): mean 19,058 \pm 1107.95 control vs $45,150.8 \pm$ 2222.46 TH mRNA transfected, 54,456.73 \pm 3015.53 

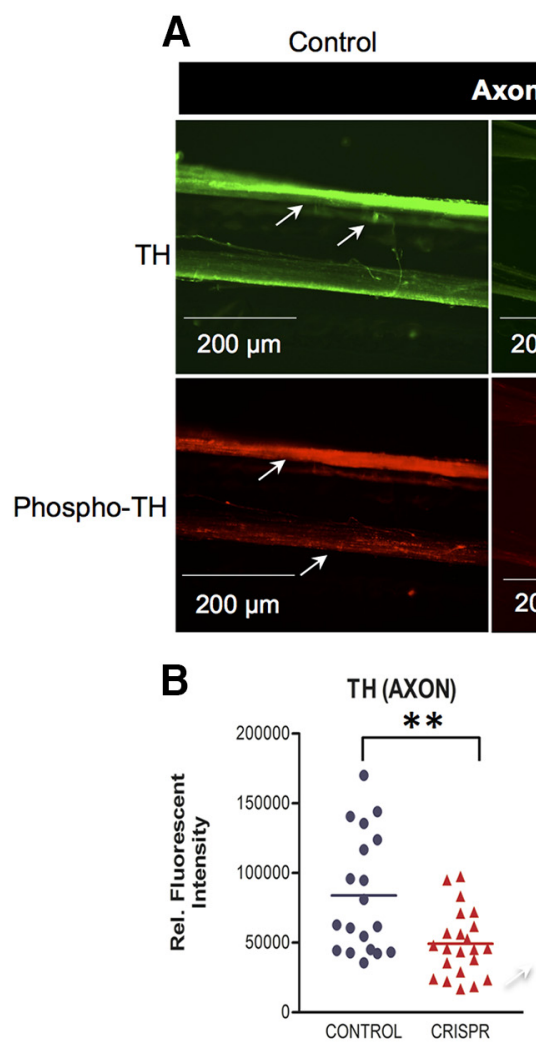

F

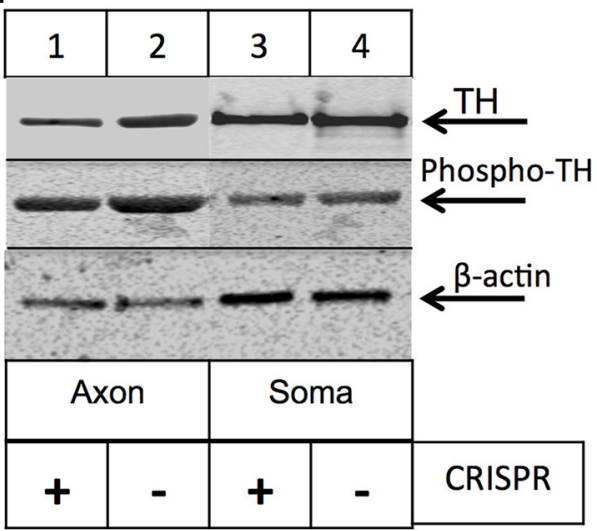

CRISPR Axons

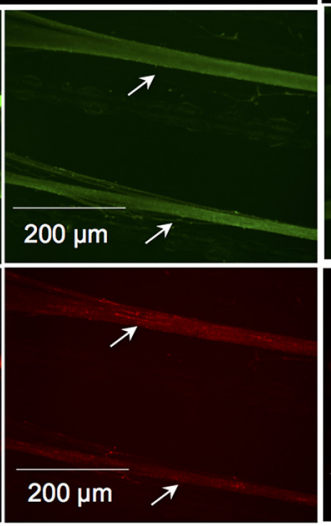

Control

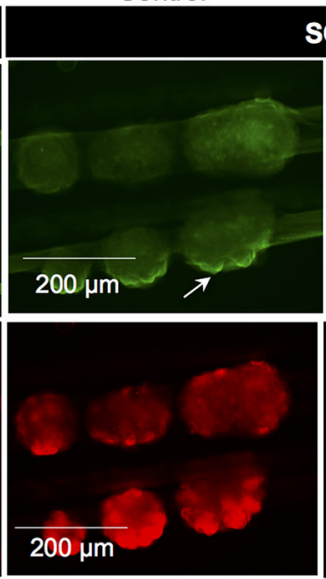

\section{CRISPR}

SOMA

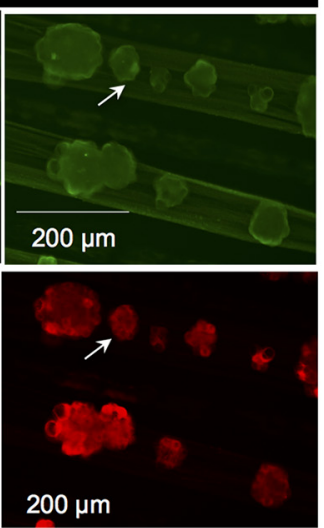

C Phospho-TH(AXON) D TH (SOMA)

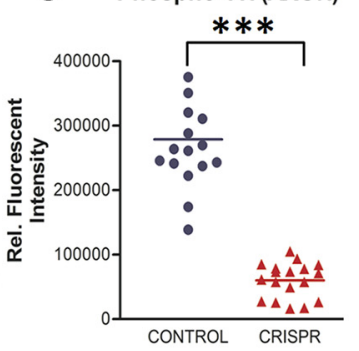

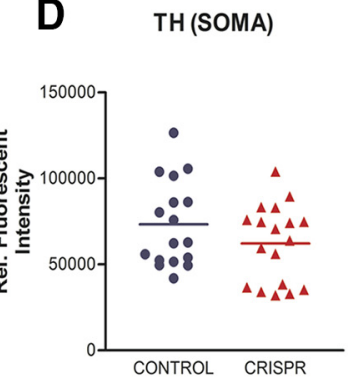

G

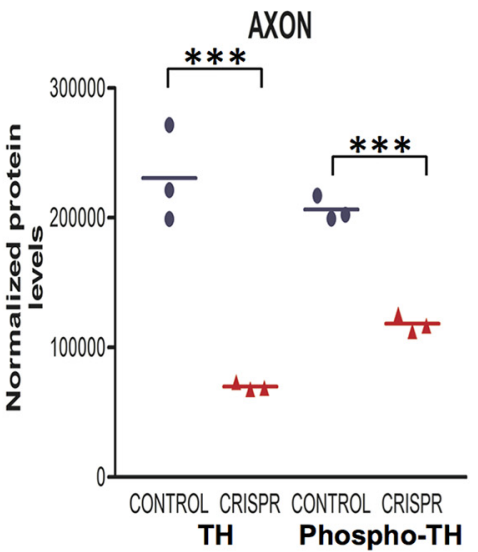

E Phospho-TH(SOMA)

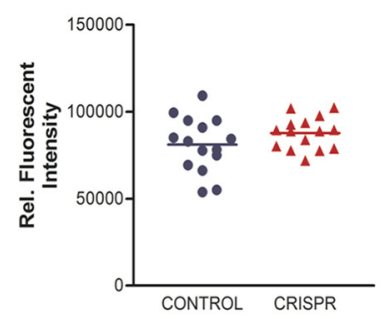

H

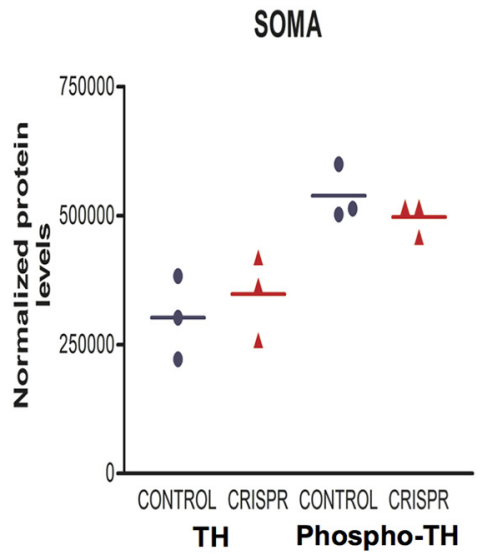

Figure 3. CRISPR-mediated deletion of the zip-code in the 3'UTR of TH mRNA selectively reduces axonal levels of TH protein and TH phosphorylation at SER40 (phospho-TH) in SCG neurons. A, Intraaxonal TH and phospho-TH levels were measured using immunocytochemistry in axons and soma of SCG neurons infected with lentiCRISPR (control) or sgRNA 1 and sgRNA 2 containing lentiCRISPR (CRISPR). Decreased TH and phospho-TH levels are detected in axons of CRISPR neurons grown in Campenot chambers. Arrows denote axonal TH and phospho-TH. B-E, Fluorescence intensity as a measure of TH $(\boldsymbol{B}, \boldsymbol{D})$ and phospho-TH $(\boldsymbol{C}, \boldsymbol{E})$ levels in axons and soma of SCG neurons were quantified using ImageJ, and fluorescence levels are provided as relative fluorescence intensity. Data are mean \pm SEM from the measurement of 18-22 axons and 16-18 SCG ganglia from three independent experiments. Student's $t$ test, $* * p \leq 0.002, * * * p \leq 0.0001$. $\boldsymbol{F}$, Western blot analysis of axonal and cell body protein lysates from SCG neurons infected with lentiCRISPR (control) or sgRNA 1 and sgRNA 2 containing lentiCRISPR (CRISPR). $\beta$-actin was used as a loading control. G, $\boldsymbol{H}, \mathrm{TH}$ and phopho-TH immunoblots of axonal or soma protein lysates of SCG neurons were quantified using ImageJ. Quantification showed significant reduction of TH and phospho-TH protein levels in axons one week after viral infection of SCG neurons grown in Campenot chambers, whereas TH and phospho-TH levels in parental cell soma remained unchanged. TH and phospho-TH band intensities were normalized to the protein levels detected for $\beta$-actin. Student's $t$ test, $* * * p \leq 0.0001$.

$\mathrm{TH}[\Delta \mathrm{ZC}] \mathrm{mRNAs}$ transfected, relative fluorescent intensity, $p \leq 0.0001 ; \mathrm{TH}$ (axon): mean 12,375.73 \pm 350.21 control vs $10,672.67 \pm 262.67 \mathrm{TH}$ mRNA transfected,
$11,158.94 \pm 468.76 \mathrm{TH}[\Delta \mathrm{ZC}] \mathrm{mRNAs}$ transfected, relative fluorescent intensity; NE (soma): mean 14,765.95 \pm 983.07 control vs 43,148.67 $\pm 1222.14 \mathrm{TH}$ mRNA trans- 


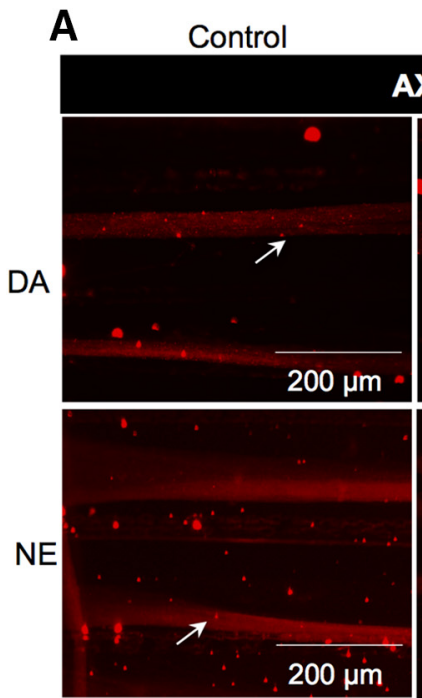

B
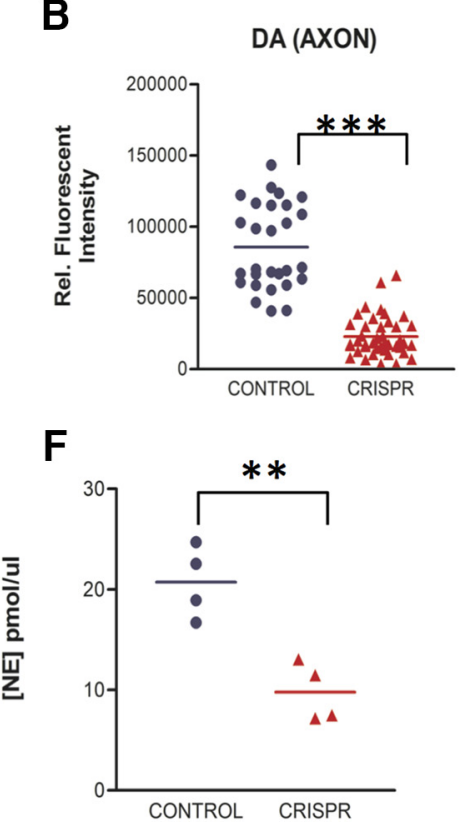

CRISPR
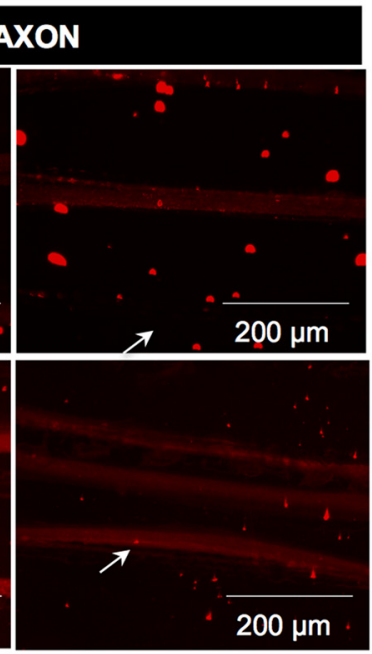

C

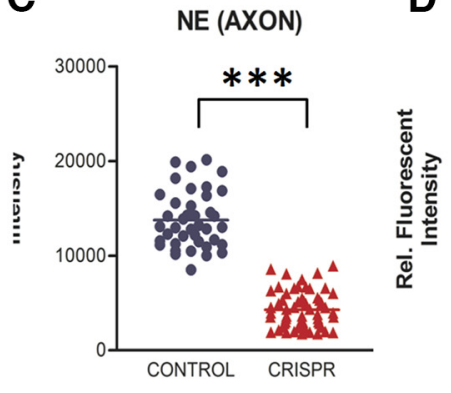

Control
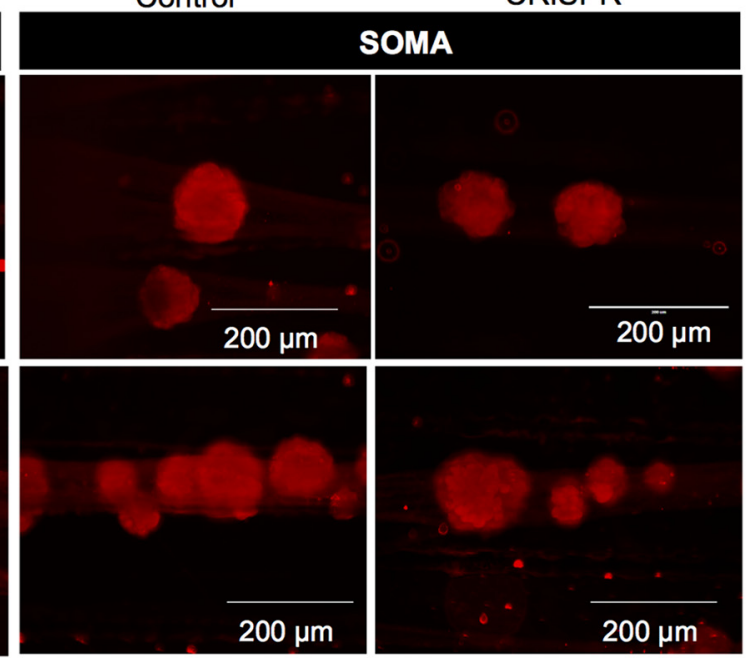

$200 \mu \mathrm{m}$
E
DA (SOMA)

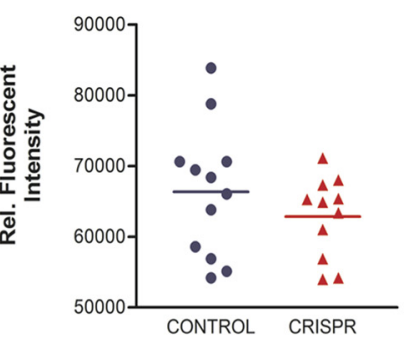

NE (SOMA)

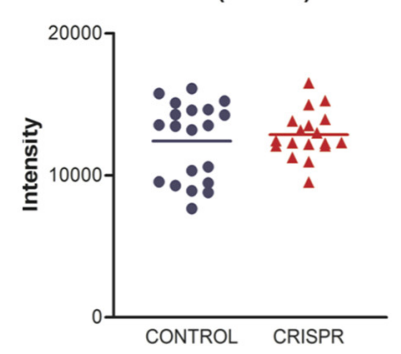

Figure 4. Reduced axonal transport of TH mRNA decreases axonal catecholamine levels in SCG axons. A, Intra-axonal DA and NE levels were measured using immunocytochemistry in axons and soma of SCG neurons infected with with lentiCRISPR (control) or sgRNA 1 and sgRNA 2 containing lentiCRSPR (CRISPR). Arrows denote axonal DA and NE. $\boldsymbol{B}-\boldsymbol{H}$, Fluorescence intensity as a measure of DA $(\boldsymbol{B}, \boldsymbol{D})$ and NE $(\boldsymbol{C}, \boldsymbol{E})$ levels was quantified in the soma and distal axons of SCG neurons, respectively, using ImageJ, and fluorescence levels are indicated as relative fluorescence intensity. Reduced DA and NE levels are detected in distal axons of CRISPR-treated neurons, whereas the parental soma DA and NE levels remained at control levels. Data are the mean \pm SEM from the measurement of neurons cultured in six Campenot chambers from three independent experiments. $\boldsymbol{F}$, Distal axons located in the lateral compartment of Campenot chambers were treated for $10 \mathrm{~min}$ with $100 \mathrm{mM} \mathrm{KCl}$. NE release into culture media was subsequently measured using an ELISA immunoassay, and NE concentration in the culture media was calculated using linear regression analysis. Reduced NE levels are detected in distal axons of CRISPR neurons, as compared with NE levels measured in the axons of control neurons. Values are mean \pm SEM of four different experiments. Student's $t$ test, $* * p \leq 0.003$.

fected, $37,420.87 \pm 2079.95 \mathrm{TH}[\Delta \mathrm{ZC}]$ mRNAs transfected, relative fluorescent intensity, $p \leq 0.0001 ; \mathrm{NE}$ (axon): mean $11,790.4 \pm 682.44$ control vs $13,085.6 \pm$ 1005.97 TH mRNA transfected, $10,661 \pm 577.89 \mathrm{TH}[\Delta \mathrm{ZC}]$ mRNAs transfected, relative fluorescent intensity; Fig. $6 F-H]$.

Taken together, our results suggest that both inhibition and augmentation of local TH synthesis bidirectionally modulates axonal TH activity and catecholamine synthesis in cultured primary sympathetic neurons.

\section{Discussion}

Previous studies demonstrated that $\mathrm{TH}$ is locally synthesized in axons, and that the axonal trafficking of $\mathrm{TH}$ mRNA is directed by a cis-acting regulatory element located in the 3'UTR of the transcript (Gervasi et al., 2016). 


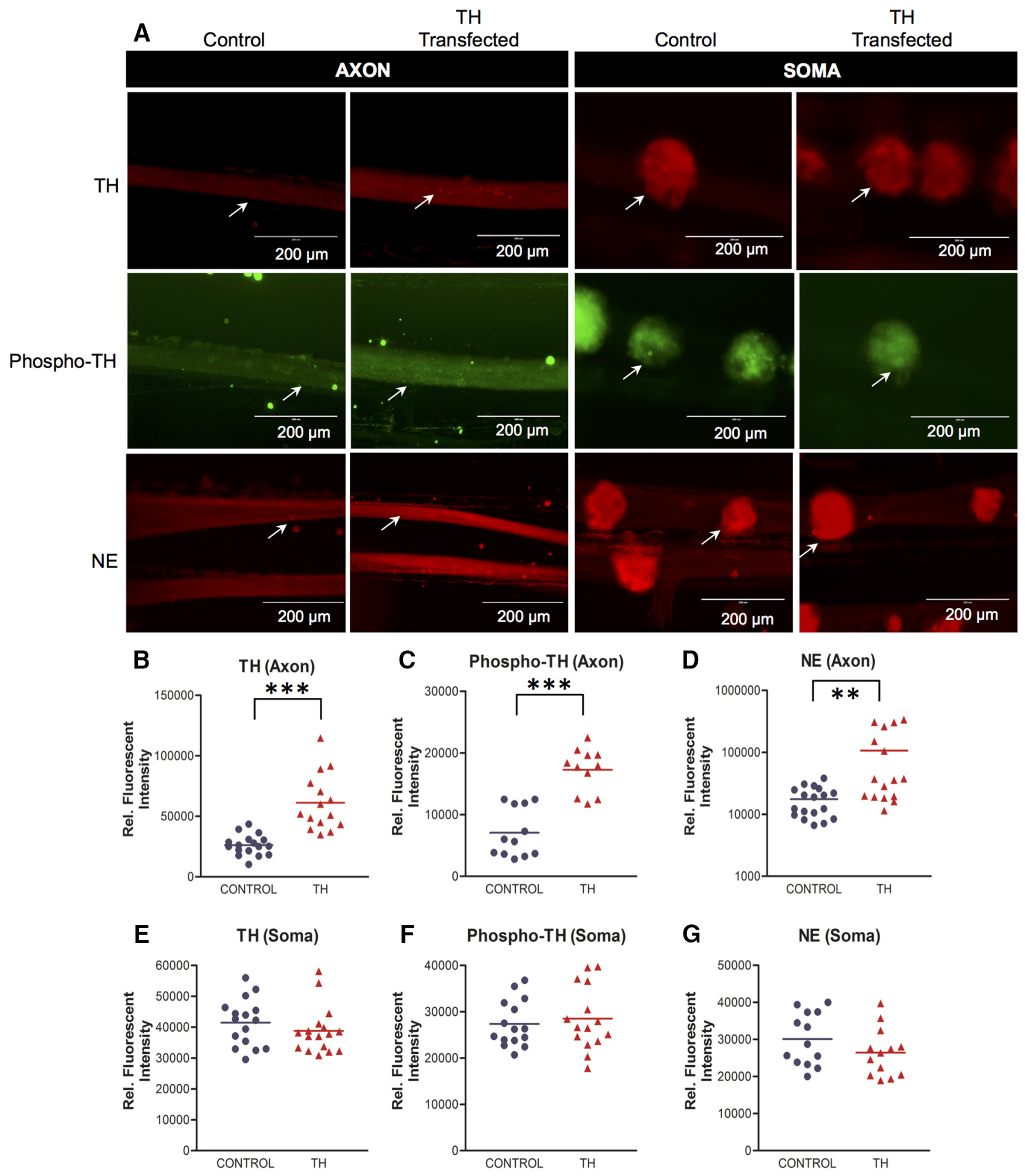

Figure 5. Local translation of TH mRNA enhances axonal levels of TH protein, TH phosphorylation at Ser40, and facilitates NE synthesis. $\boldsymbol{A}$, Intra-axonal $\mathrm{TH}$, phospho- $\mathrm{TH}$, and $\mathrm{NE}$ levels were measured $2 \mathrm{~d}$ after transfection using immunocytochemistry in axons lipofected with $\mathrm{TH}$ mRNA or sham-transfected controls. Increased levels of TH, phospho-TH and NE are detected in axons locally overexpressing TH, whereas the soma levels of TH, phospho-TH and NE remained at control levels. Arrows, denote axonal TH, phospho-TH and NE. B-D, Fluorescence intensity as a measure of TH $(\boldsymbol{B})$, phospho-TH $(\boldsymbol{C})$, and NE $(\boldsymbol{D})$ levels was quantified in the axons of SCG neurons using ImageJ, and fluorescence levels are provided as relative fluorescence intensity. Data are mean \pm SEM from the measurement of 16-22 axons from three independent experiments. Student's $t$ test, $* * p \leq 0.004 ; * * * p \leq 0.0001$. $\boldsymbol{E}-\mathbf{G}$, Fluorescence intensity as a measure of TH $(\boldsymbol{B})$, phospho-TH, and NE $(\boldsymbol{D})$ levels was quantified in the soma of SCG neurons using ImageJ, and fluorescence levels are provided as relative fluorescence intensity. Data are the mean \pm SEM from the measurement of 16-22 SCG ganglia from three independent experiments. 

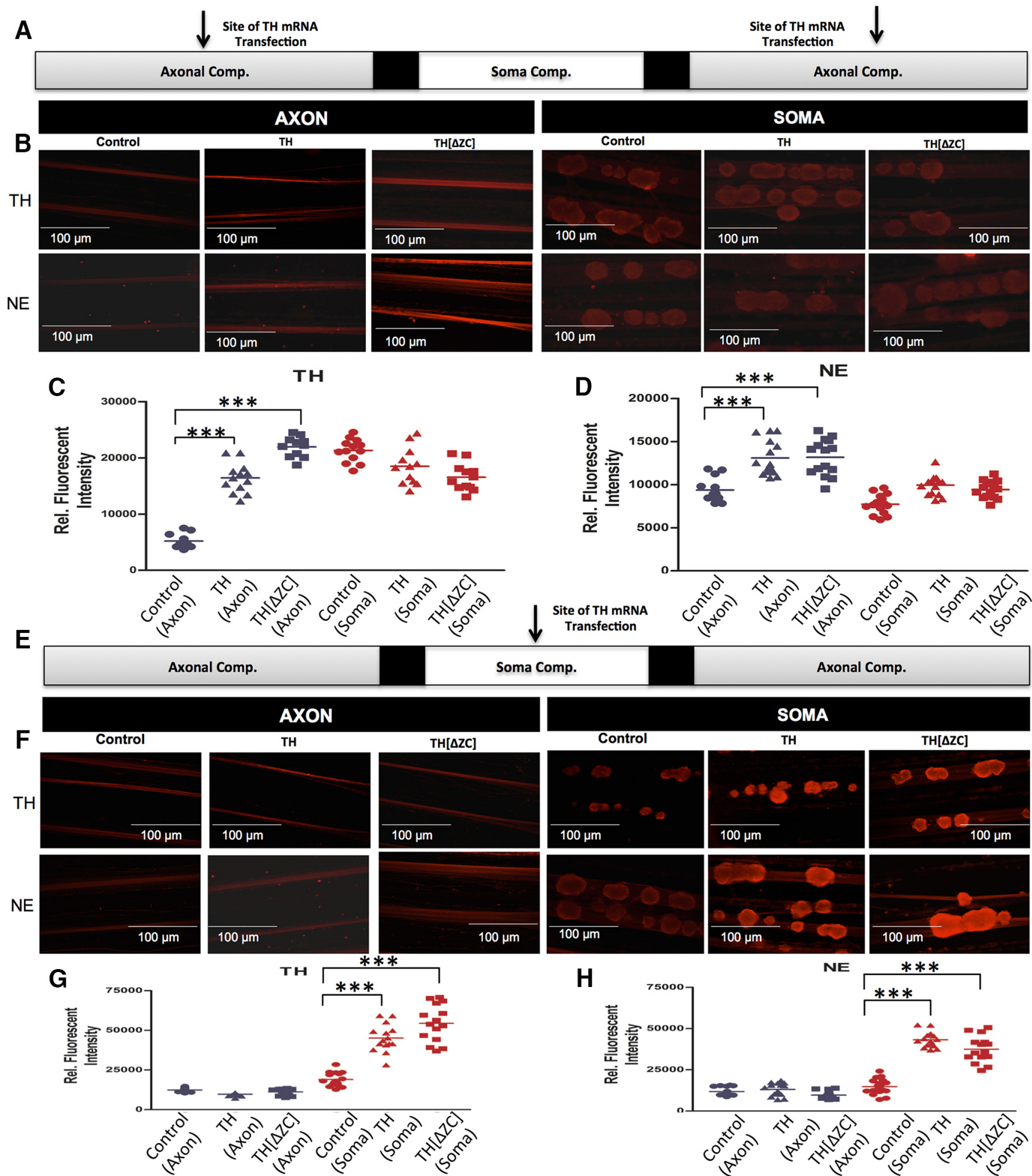

H

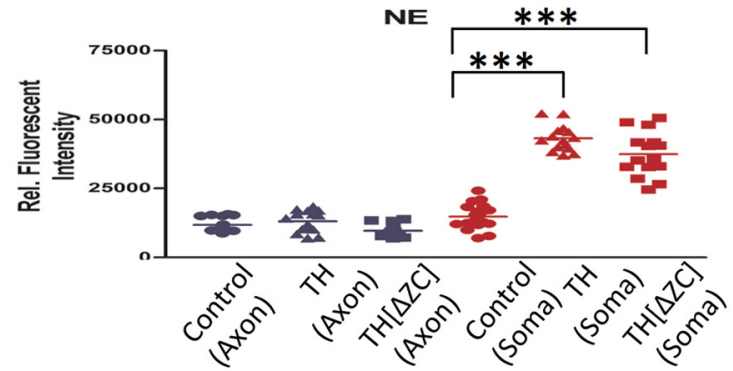

Figure 6. Intact and zip-code-less TH mRNAs are locally translated, enhance axonal levels of TH proteins and facilitate presynaptic NE synthesis. $\boldsymbol{A}$, Schematic representation of the Campenot culture chambers, the sites of mRNA transfection are indicated with arrows. $\boldsymbol{B}$, Intra-axonal and soma TH and NE levels were measured $1 \mathrm{~d}$ after transfection, using immunocytochemistry in soma and axons, in which axons were lipofected with intact or zip-code-less TH mRNA or sham transfected. Increased levels of TH and NE are detected in axons locally overexpressing $\mathrm{TH}$, whereas the soma levels of $\mathrm{TH}$, and NE remained at control levels. $\boldsymbol{C}, \boldsymbol{D}$, Fluorescence intensity as a measure of TH $(\boldsymbol{C})$ and NE $(\boldsymbol{D})$ was quantified in the axons and soma of SCG neurons using ImageJ. Fluorescence levels are provided as relative fluorescence intensity. Data are mean \pm SEM from the measurement of 16-22 axons and 16-18 SCG ganglia from three independent experiments. One-way ANOVA, $* * * p \leq 0.0001$. E, Schematic representation of the Campenot culture chambers, the site of mRNA transfection in the center compartment is indicated with an arrow. $\boldsymbol{F}$, Intra-axonal and soma TH and NE 


\section{continued}

levels were measured $1 \mathrm{~d}$ after transfection, using immunocytochemistry in axons and cognate soma, in which soma were lipofected with intact or zip-code-less TH mRNA. Sham-transfected neurons served as negative controls. Increased levels of TH and NE are detected in soma and proximal axons locally overexpressing $\mathrm{TH}$, whereas the distal axon levels of $\mathrm{TH}$, and $\mathrm{NE}$ remained at control levels. $\boldsymbol{G}, \boldsymbol{H}$, Fluorescence intensity as a measure of TH $(\boldsymbol{G})$ and NE $(\boldsymbol{H})$ levels was quantified in the axons and soma of SCG neurons using ImageJ, and fluorescence levels are provided as relative fluorescence intensity. Data are the mean \pm SEM from the measurement of 16-22 axons and 16-18 SCG ganglia from three independent experiments. One-way ANOVA, ***p $\leq 0.0001$.

In this report, evidence is provided to indicate that the zip-code plays a critical role in axonal TH mRNA trafficking and local TH synthesis in primary rat sympathetic neurons. Using CRISPR/Cas9-mediated gene editing, the axonal trafficking sequences located in the 3'UTR of TH mRNA were deleted. Genomic removal of this cis-acting regulatory element resulted in diminished axonal TH mRNA transport and local synthesis of TH. In this regard, it is postulated that this axonal localization signal functions as a nucleation site for the formation of ribonucleoprotein (RNP) complexes. These complexes are likely formed shortly after transcription and regulate the messages' translation in the distal axonal compartment (Eom et al., 2003). Indeed, the results derived from in situ hybridization experiments suggest the presence of $\mathrm{TH}$ mRNA containing RNP puncta in distal axons of SCG neurons, which disappear on the genomic deletion of the zip-code: these findings suggest an essential role for the zip-code in the assembly of TH mRNA containing RNPs. At this time, one can only speculate on the composition of the RBPs, which bind to TH mRNA. Future studies employing RNA affinity pull-down-coupled mass spectrometry are likely to identify the RBPs which are enriched in the TH mRNA binding complex, as well as regulatory proteins that modulate the local translation of TH mRNA. In addition, RNA affinity purification, Western blot analyses, and siRNA-mediated knockdown experiments may prove useful in demonstrating that the TH zip-code indeed interacts with many trans-acting RBPs and that the expression of these proteins can modulate the transport of the TH transcript to the axon.

The control of the synthesis of catecholamine neurotransmitters is of fundamental importance, since changes in DA metabolism are associated with many neurologic disorders (Weinberger, 1987). The outcome of this study suggested that CRISPR-mediated deletion of the zip-code reduced axonal TH levels, TH phosphorylation at SER40, as well as diminished the axonal levels and release of NE. These findings suggest that the synthesis of the catecholamine neurotransmitters could be regulated locally in the terminal fields situated far distant from the parental cell soma. Interestingly, previous studies indicated that $\mathrm{TH}$ gene transcription and enzyme activation is sensitive to fast membrane potential changes and intracellular $\mathrm{Ca}^{2+}$-transients, that is, those associated with normal rates and patterns of neuronal activity (Aumann and Horne, 2012). More recently, a number of studies have also provided support for an activitydependent regulation of axonal synthesis of proteins that play a critical role in the functioning of the presynaptic nerve terminals (Antar et al., 2006; Gomes et al., 2014). Although currently there is no evidence for an activitydependent role for local TH synthesis, a recent post- mortem study assessing anomalies of the dopaminergic system in schizophrenia showed that $\mathrm{TH}$ protein levels were abnormal in schizophrenia, while mRNA expression levels were not affected, indicating that TH pathology in the substantia nigra/ventral tegmental area may occur post-transcriptionally (Perez-Costas et al., 2012). Interestingly, the administration of reserpine, a powerful catecholamine depleting agent, markedly enhanced TH mRNA levels in the cerebellum, a finding that raised the possibility that the local synthesis of $\mathrm{TH}$ might function to facilitate the restoration of neurotransmitter levels (Melia et al., 1994). In addition, in midbrain dopaminergic neurons, TH synthesis can be regulated at the translational level and synthesis of the enzyme can be induced in a cyclic AMP-dependent manner in the absence of alteration in mRNA levels (Chen et al., 2008). Taken together, these findings, along with the results shown in this report, raise the intriguing possibility that the synthesis of the catecholamine neurotransmitters could be regulated locally in the presynaptic nerve terminal.

Previous research suggested a neuromodulatory role for Angiotensin II (Ang II) on TH and DA- $\beta$-hydroxylase $(\mathrm{D} \beta \mathrm{H})$ actions, in part, by influencing the transcription of their genes (Gelband et al., 1998). The diverse physiologic effects of Ang II on catecholamine synthesis are mediated by its interaction with the angiotensin type 1 receptor subtype ( $\mathrm{AT}_{1}$ receptor) coupled with the MAP kinase signaling pathway, which regulates enhanced neuromodulatory actions of Ang II including stimulation of $\mathrm{TH}, \mathrm{D} \beta \mathrm{H}$, and NE transporter (Duff et al., 1995). Interestingly, the MAPK family includes signal-transducing enzymes that are involved in many aspects of cellular responses, including cue-mediated local protein synthesis in distal axons and dendrites. The activation of translation initiation regulators (i.e., phosphorylation of elF-4E, elF-4EBP1, and Mnk-1) in growth cones is dependent on p42/p44 and p38 MAPK (Campbell and Holt, 2003; Kelleher et al., 2004). Moreover, the local synthesis of nascent TH protein in distal axons may provide a critical entity for enzyme activation through a series of phosphorylation events mediated by upstream signaling, including ANG II-induced signaling, at the site of neurotransmitter release. Given the nature of Ang II function to chronically exert diverse physiologic actions in both peripheral and control neural tissues by activating the catecholamine synthetic machinery, it is tempting to speculate that ANG II regulation of local translation may result in the local synthesis of $\mathrm{TH}$ in the distal axons.

At present, whether mRNAs encoding the biosynthetic enzymes regulating the synthesis of other amino acidderived neurotransmitters is unknown. However, mRNAs coding for the neuropeptides oxytocin, vasopressin and 
dynorphin are transported to the distal axons of peptidergic neurons comprising the hypothalamo-hypophyseal tract (Mohr et al., 1991). Hence, it is possible that mRNAs coding for a wide variety of neurotransmitters and/or neuromodulatory substances can be functioning locally in the axon and presynaptic nerve terminal.

In conclusion, the outcome of this study demonstrates that the local synthesis of TH can modulate the levels of catecholamines in the axon and nerve terminal, and raises the possibility that trafficking and local synthesis of $\mathrm{TH}$ mRNA may act to facilitate the restoration of neurotransmitter levels under conditions of prolonged release.

\section{References}

Antar LN, Li C, Zhang H, Carroll RC, Bassell GJ (2006) Local functions for FMRP in axon growth cone motility and activitydependent regulation of filopodia and spine synapses. Mol Cell Neurosci 32:37-48. CrossRef Medline

Aschrafi A, Natera-Naranjo O, Gioio AE, Kaplan BB (2010) Regulation of axonal trafficking of cytochrome $c$ oxidase IV mRNA. Mol Cell Neurosci 43:422-430. CrossRef Medline

Aumann T, Horne M (2012) Activity-dependent regulation of the dopamine phenotype in substantia nigra neurons. $J$ Neurochem 121:497-515. CrossRef Medline

Bevilaqua LR, Graham ME, Dunkley PR, von Nagy-Felsobuki El, Dickson PW (2001) Phosphorylation of Ser(19) alters the conformation of tyrosine hydroxylase to increase the rate of phosphorylation of Ser(40). J Biol Chem 276:40411-40416. CrossRef

Bobrovskaya L, Dunkley PR, Dickson PW (2004) Phosphorylation of Ser19 increases both Ser40 phosphorylation and enzyme activity of tyrosine hydroxylase in intact cells. J Neurochem 90:857-864. CrossRef

Burgess A, Vigneron S, Brioudes E, Labbé JC, Lorca T, Castro A (2010) Loss of human Greatwall results in G2 arrest and multiple mitotic defects due to deregulation of the cyclin B-Cdc2/PP2A balance. Proc Natl Acad Sci USA 107:12564-12569. CrossRef Medline

Campbell DS, Holt CE (2003) Apoptotic pathway and MAPKs differentially regulate chemotropic responses of retinal growth cones. Neuron 37:939-952. Medline

Chen X, Xu L, Radcliffe P, Sun B, Tank AW (2008) Activation of tyrosine hydroxylase mRNA translation by cAMP in midbrain dopaminergic neurons. Mol Pharmacol 73:1816-1828. CrossRef Medline

Di Liegro CM, Schiera G, Di Liegro I (2014) Regulation of mRNA transport, localization and translation in the nervous system of mammals (review). Int J Mol Med 33:747-762. CrossRef Medline

Duff JL, Marrero MB, Paxton WG, Schieffer B, Bernstein KE, Berk BC (1995) Angiotensin II signal transduction and the mitogenactivated protein kinase pathway. Cardiovasc Res 30:511-517. Medline

Eom T, Antar LN, Singer RH, Bassell GJ (2003) Localization of a beta-actin messenger ribonucleoprotein complex with zip-codebinding protein modulates the density of dendritic filopodia and filopodial synapses 22. J Neurosci 23:10433-10444.

Fallini C, Donlin-Asp PG, Rouanet JP, Bassell GJ, Rossoll W (2016) Deficiency of the survival of motor neuron protein impairs mRNA localization and local translation in the growth cone of motor neurons. J Neurosci 36:3811-3820. CrossRef Medline

Gelband CH, Sumners C, Lu D, Raizada MK (1998) Angiotensin receptors and norepinephrine neuromodulation: implications of functional coupling. Regul Pept 73:141-147. Medline

Gervasi NM, Scott SS, Aschrafi A, Gale J, Vohra SN, MacGibeny MA, Kar AN, Gioio AE, Kaplan BB (2016) The local expression and trafficking of tyrosine hydroxylase mRNA in the axons of sympathetic neurons. RNA 22:883-895. CrossRef Medline

Gomes C, Merianda TT, Lee SJ, Yoo S, Twiss JL (2014) Molecular determinants of the axonal mRNA transcriptome. Dev Neurobiol 74:218-232. CrossRef Medline

Han Y, Slivano OJ, Christie CK, Cheng AW, Miano JM (2015) CRISPR-Cas9 genome editing of a single regulatory element nearly abolishes target gene expression in mice-brief report. Arterioscler Thromb Vasc Biol 35:312-315. CrossRef

Hillefors M, Gioio AE, Mameza MG, Kaplan BB (2007) Axon viability and mitochondrial function are dependent on local protein synthesis in sympathetic neurons. Cell Mol Neurobiol 27:701-716. CrossRef Medline

Hsu PD, Lander ES, Zhang F (2014) Development and applications of CRISPR-Cas9 for genome engineering. Cell 157:1262-1278. CrossRef Medline

Jung H, Gkogkas CG, Sonenberg N, Holt CE (2014) Remote control of gene function by local translation. Cell 157:26-40. CrossRef Medline

Kaplan BB, Gioio AE, Hillefors M, Aschrafi A (2009) Axonal protein synthesis and the regulation of local mitochondrial function. Results Probl Cell Differ 48:225-242. CrossRef Medline

Kelleher RJ, III, Govindarajan A, Jung HY, Kang H, Tonegawa S (2004) Translational control by MAPK signaling in long-term synaptic plasticity and memory. Cell 116:467-479. CrossRef

Lewis DA, Melchitzky DS, Gioio A, Solomon Z, Kaplan BB (1991) Neuronal localization of tyrosine hydroxylase gene products in human neocortex. Mol Cell Neurosci 2:228-234. Medline

McCloy RA, Rogers S, Caldon CE, Lorca T, Castro A, Burgess A (2014) Partial inhibition of Cdk1 in G 2 phase overrides the SAC and decouples mitotic events. Cell Cycle 13:1400-1412. CrossRef

Melia KR, Trembleau A, Oddi R, Sanna PP, Bloom FE (1994) Detection and regulation of tyrosine hydroxylase mRNA in catecholaminergic terminal fields: possible axonal compartmentalization. Exp Neurol 130:394-406. CrossRef Medline

Mohr E, Fehr S, Richter D (1991) Axonal transport of neuropeptide encoding mRNAs within the hypothalamo-hypophyseal tract of rats. EMBO J 10:2419-2424. Medline

Perez-Costas E, Melendez-Ferro M, Rice MW, Conley RR, Roberts RC (2012) Dopamine pathology in schizophrenia: analysis of total and phosphorylated tyrosine hydroxylase in the substantia nigra. Front Psychiatry 3:31. CrossRef Medline

Sanjana NE, Shalem O, Zhang F (2014) Improved vectors and genome-wide libraries for CRISPR screening. Nat Methods 11: 783-784. CrossRef Medline

Scott SS, Gervasi NM, Kaplan BB (2015) Subcellular compartmentalization of neuronal RNAs: an overview. Trends Cell Mol Biol 1-36.

Smart F, Aschrafi A, Atkins A, Owens GC, Pilotte J, Cunningham BA, Vanderklish PW (2007) Two isoforms of the cold-inducible mRNAbinding protein RBM3 localize to dendrites and promote translation. J Neurochem 101:1367-1379. CrossRef Medline

Weinberger DR (1987) Implications of normal brain development for the pathogenesis of schizophrenia. Arch Gen Psychiatry 44:660669. Medline 